\title{
CLINICAL AND RADIOGRAPHIC EVALUATION OF THE OSSEOINTEGRATION, BONE LEVEL, BONE DENSITY AROUND SHORT DENTAL IMPLANTS IN POSTERIOR ATROPHIC MAXILLA
}

\author{
Gamalat A Harby ${ }^{1}$, Sherif H El Ghamrawy ${ }^{2}$, Tarek M Aly ${ }^{2}$
}

\begin{abstract}
INTRODUCTION: Edentulous ridge in the posterior maxilla is often compromised by reduced bone volume. This anatomical condition limits the implant placement without sinus augmentation. The use of short implant minimizes the need of more extensive sinus floor elevation, thus reducing the duration and morbidity of the treatment.

OBJECTIVE: This study was designed to evaluate the osseointegration, bone level and bone density around short dental implants in posterior atrophic maxilla.

MATERIALS AND METHODS: Twenty short implants (Euroteknika-74700 sallanches-FRANCE) were inserted in posterior atrophic maxilla in ten adult patients. The bone density of implants recipient sites was determined by gray scale using CBCT. The implants' stability was measured by resonance frequency analysis using Osstell ISQ. The bone level around the implant was measured by image J program. The values were determined immediately post-operatively and on intervals of $1,3 \& 6$ months.

RESULTS: The mean bone density value was $(1522.0 \pm 137.14)$ at the site of implant placement preoperatively and (1649.50 \pm 102.93$)$, $(1832.95 \pm 92.41),(1934.25 \pm 82.72)$ at $1^{\text {st }}, 3^{\text {rd }}$ and $6^{\text {th }}$ months postoperative respectively, there was a statistical significant increase. The mean implant stability value was $(60.30+6.09)$ immediately post-operatively, then increased to $(70.06 \pm 4.61)$ on the 6 th month, there was a statistical significant increase. The marginal bone level immediately postoperatively was $(0.54 \pm 0.10 \mathrm{~mm})$, on the $3^{\text {rd }}$ month it was $(0.62 \pm 0.12 \mathrm{~mm})$, on the $6^{\text {th }}$ month it was $(0.69 \pm 0.15 \mathrm{~mm})$ and on the $9^{\text {th }}$ month it was $(0.79 \pm 0.21 \mathrm{~mm})$. There was a statistically significant increase.

CONCLUSION: This study suggests that short implants might be a preferable choice to place in atrophic posterior maxilla since the treatment is faster, cheaper and associated with less morbidity, however their long-term prognosis is unknown.

KEY WORDS: Atrophic maxilla, Short implant, Bone density, Marginal bone level, Implant stability.
\end{abstract}

1. Dentist, Faculty of Dentistry, Alexandria University, Egypt

2. Professor at Department of Oral and Maxillofacial surgery, Faculty of Dentistry, Alexandria University, Egypt.

\section{INTRODUCTION}

Partial edentation of posterior jaw region is a common problem. The missing dentition can be replaced by partial removable dentures, though they are poorly tolerated because of their instability and discomfort. The ideal solution would be an implant-supported fixed prosthesis. Unfortunately, posterior jaws often have insufficient bone height to place dental implants of adequate length due to anatomical limitation such as inferior alveolar nerve or pneumutized maxillary sinus. Ten to twelve mm of bone height of adequate thickness is generally considered sufficient to allow placement of dental implants of length $(9$ to $11 \mathrm{~mm}$ ) sufficient to guarantee a good long-term prognosis of implant supported prosthesis. Unfortunately, often the residual amount of bone in the posterior jaws is less than $10 \mathrm{~mm}(1,2)$.

In these situations the dentist is faced with the dilemma of whether to augment the bone or to use short implants (8mm or less).

Various techniques are used to augment the posterior mandible and maxilla $(3,4)$. There is a large variation in the augmentation procedures. With materials and biologically

active factors, superiority of a certain technique/material over any other is still lacking $(3,4)$. It appears, however, that bone substitutes can be successfully used as an alternative to autogenous bone since patient discomfort is reduced $(3,5$ 8). Other general limitations of augmentation procedures are that they are technically demanding and therefore require skillful operators, are often associated with significant post-operative morbidity and complications, can be expensive, and may require a long term (up to 1 year) before patients are able to chew on their implants supported prosthesis $(1,4)$.

Implant lengths of $7 \mathrm{~mm}$ or shorter may not have a good long-term prognosis when compared with longer implants; however, short implant could be a simpler, cheaper and faster alternative to augmentation procedures of posterior jaws (1).

The definition of 'short' implants is controversial since some authors consider as 'short' all those implants with a length ranging between 7 to $10 \mathrm{~mm}$ whereas other authors consider 'short' those implant with a designed intra-bony length of $8 \mathrm{~mm}$ or less. Implants with lengths varying from 5 to $8 \mathrm{~mm}$ are currently used, and there are only a few short term comparative studies evaluating their efficacy in a reliable way $(8,9)$.

The success of dental implants depends on the concept of osseointegration introduced by Branemark which implies the structural and functional contact between the implant and the surrounding vital bone (10).

The stability of dental implants can be defined as the absence of clinical mobility and this is also the suggested definition of osseointegration (11).

The most important prerequisite for success of osseointegrated dental implants is the achievement and maintenance of implant stability (11). Primary stability is a merely mechanical phenomenon depending upon local bone quality, quantity, surgical technique, and implant design 
$(12,13)$ are the most important factors in the osseointegration process.

The implant surface, including topography, chemistry, surface charge, and wettability, have been described as important factors to influence osseointegration (14).

The clinical measurement of implant stability and osseointegration is important to be able to assess success in implant dentistry (15).

This study was designed to evaluate the osseointegration, bone level and bone density around short implants in posterior atrophic maxilla.

\section{MATERIALS AND METHODS}

A clinical trial was conducted on ten adult patients of both sexes ( 8 males and 2 females) having missing maxillary posterior teeth indicated for implant rehabilitation. The patients were selected from the Outpatient Clinic of the Oral \& Maxillofacial Surgery Department, Faculty of Dentistry, Alexandria University.

\section{Criteria of selection}

The inclusion criteria of this study were: patients having good oral hygiene, patients were psychologically accepting the implant and the involved procedures, the implant sites were free from pathological conditions, patients having adequate inter-occlusal distance to accommodate the fixed prosthesis after implant placement, patients having adequate bone height $(6-9 \mathrm{~mm})$ and sufficient width to accommodate implant placement.

While the exclusion criteria of this study were: immunosuppressed or immunocompromised, patients subjected to irradiation of head and neck, uncontrolled diabetes, patient with parafunctional habits, such as bruxism and clenching, heavy smokers and alcoholism.

A signed informed consent was obtained from all patients and the study was approved by the Oral and Maxillofacial Surgery research committee and the ethical committee of the Faculty of Dentistry, Alexandria University.

\section{Implant system}

Implant system (Euroteknika-74700 sallanches-FRANCE) it's a short Implant (NATEA $4.8 \mathrm{~mm}$ diameter $\times 6 \mathrm{~mm}$ length) two pieces (submerged) was used in this study.

The implants are sandblasted with ceramic balls and etched with nitric and hydrofluoric acids. They have Micro threads to reduce marginal bone resorption. They also have double threads to limit bone heating following implant insertion as each thread cuts into half the bony wall of the preparation site. They have conical with internal Hex connection, as well as platform switching, which helps to minimize bone loss that can reduce peak-stress and thereby preserve marginal bone. It is effective to establish a certain biological width of the peri-implant mucosa.

\section{Osstell ISQ}

Osstell ISQ system (Osstell ${ }^{\circledR}$, integration Diagnostic AB, Goteborg, Sweden) consist of osstell ISQ instrument, probe, charger, USB cable and test peg. Osstell ISQ was used for measurement of implant stability.

The system includes the use of a SmartPeg ${ }^{\mathrm{TM}}$ attached to the dental implant or abutment by means of an integrated screw. The SmartPeg is excited by a magnetic pulse from the measurement probe on the handheld instrument. The resonance frequency, which is the measure of implant stability, is calculated from the response signal. Results are displayed on the instrument as the Implant Stability Quotient
(ISQ), which is scaled from 1 to 100 . The higher the value, the more stable the implant.

\section{Preoperative Phase}

Detailed preoperative data were collected from all patients including: name, age, gender, occupation and address, past and present medical history, dental history that included etiology of tooth loss and habits.

\section{Clinical Examination}

The clinical examination included:

Inspection of oral and para oral tissues was performed to evaluate: existing alveolar contour, height, and width, soft tissue attachments for any signs of inflammation, ulceration or scar formation, existing pathology, palatal vault dimension, vestibular depth.

Palpation of the alveolar ridge performed to evaluate: Identification of both soft tissue and underlying bone characteristics, determinant of loose and excessive soft tissue, identification of occult bony abnormalities obscured by soft tissue excess.

Alginate impressions were taken for the patients, and study casts were constructed as a pretreatment record for all patients. Study casts were used to evaluate occlusal centric relation position, edentulous ridge relationships to adjacent teeth and opposing arch, and the interarch space. Also, they were used for construction of surgical stents.

\section{Radiographic examination}

Standardized periapical radiograph films, orthopantomogram (OPG), cone beam computed tomography (CBCT.

All patients underwent pre-operative $\mathrm{CBCT}$ to determine the bone height at the implant site, bone thickness and bone density (Fig. 1).

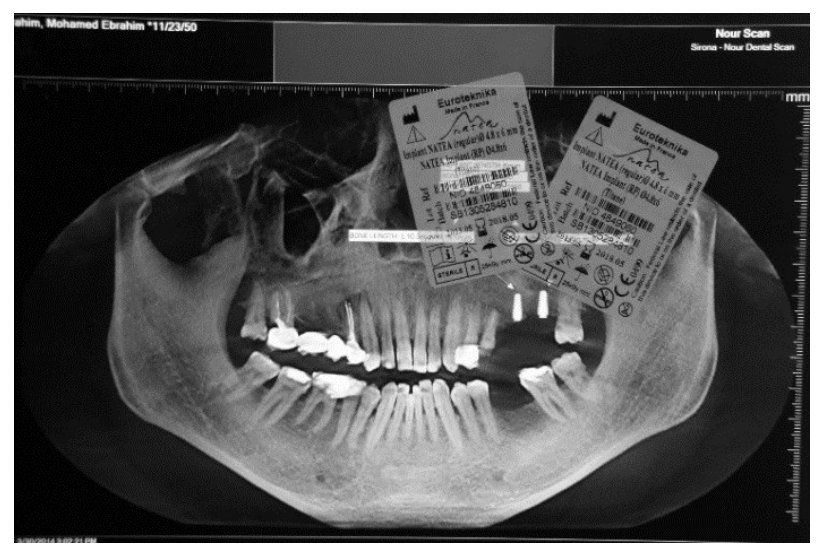

Figure 1: Preoperative CBCT image showing missing maxillary left first and second molar teeth.

\section{A- Preoperative instructions}

All patients received strict oral hygiene instruction to maintain periodontal health in the form of oral rinses with chlorhexidine mouthwash $0.12 \%$ (Hexitol Mouthwash, the Arab drug co., Cairo, Egypt).

\section{B- Operative Phase}

The operation was carried out under local anesthesia. The patients were asked to thoroughly rinse with an antiseptic solution chlorhexidine gluconate mouth wash for 30 seconds before surgical procedure.

Infiltration Anesthesia (Mepecaine - L Cartridges) (mepivacaine HCL 2\% with levonordefrin 1: 20,000) (Alexandria Co. for pharmaceuticals \& Chemical industries Alex. - Egypt) was used in maxilla. The anesthetic technique used was the supraperiosteal or paraperiosteal infiltration anesthesia). 
The oral cavity was swabbed using Povidone-iodine (PVP-I) (Betadine, Nile drug company, Cairo, Egypt.) antiseptic solution and the patient was draped using sterile towels according to the standard technique of intraoral surgeries.

An incision was made palatal to the crest of the ridge using bard parker blade \#15 on the midline of the gingiva attached to the edentulous ridge and extended for several millimeters beyond the osteotomy area. A mesio-vertical releasing incision was performed for better visualization of the operative field, the full thickness mucoperiostal flap was reflected to expose the ridge.

The implant site was marked using a surgical template and osteotomy were performed using Pilot drill with copious amount of coolant to guide the rest of the drills in correct position and angulations. The surgical stent was removed then drills were used in a sequential manner till the required diameter for the fixture was reached. The final drill was performed with a smaller diameter than the final implant diameter according to the manufacturer instructions

The implant fixture was inserted into the prepared osteotomy by its plastic holder and turned in a clockwise direction till difficulty is encountered. This was followed by the use of an Over hex driver and ratchet wrench, till the implant body was flushed with the bone surface.

The smartpeg was attached to the dental implant, the implant stability was measured by osstell ISQ then the cover screw was placed. The flap was then repositioned and the edges were sutured using 3/0 black silk suture (Fig. 2).

\section{Postoperative phase}

Postoperative Medication: all patients received the following medications:

Anti-biotic: amoxicillin trihydrate (Hiconcil 500mg, Pharco, Alexandria, Egypt.) 500 mg, 1 capsule every 8 hours for 4 days post operatively.

Analgesics: Ibuprofen (Manufacturer's PIL, Brufen ${ }^{\circledR}$ tablets, Abbott laboratories limited, electronic medicines compendium) $400 \mathrm{mg}$ was prescribed to take 2 to 4 times a day during meal.

Mouthwash: Patient instructed to use chlorhexdine mouthwash for 1 minute twice a day for 2 weeks starting on the $2^{\text {nd }}$ postoperative day.

Postoperative Instructions: all patients were instructed by the following instructions:

Apply cold packs extra orally intermittently every 10 minutes for 2 hours on the first day to have soft diet for one week, avoid brushing and trauma.

Any prosthesis was not allowed to be worn until they had been adjusted and refitted not sooner than 2 weeks after surgery.

Sutures were removed after 7 days.

\section{A. Clinical Evaluation}

Clinical and radiographic evaluation were performed for each patient immediately after implant placement and at intervals of 1, 3 and 6 months. The clinical phase were extended to 9 and 12 months.

1. Presence of pain, tenderness or discomfort: pain was evaluated using Visual Analogue Scale (16) (VAS). It's a horizontal line, $100 \mathrm{~mm}$ in length, anchored by word descriptors at each end. The patients mark on the line the point that they feel represents their perception of their current state. The VAS score is determined by measuring in millimeters from the left hand end of the line to the point that the patient marks. Tenderness and discomfort were evaluated according to the signs and symptoms of the patients.

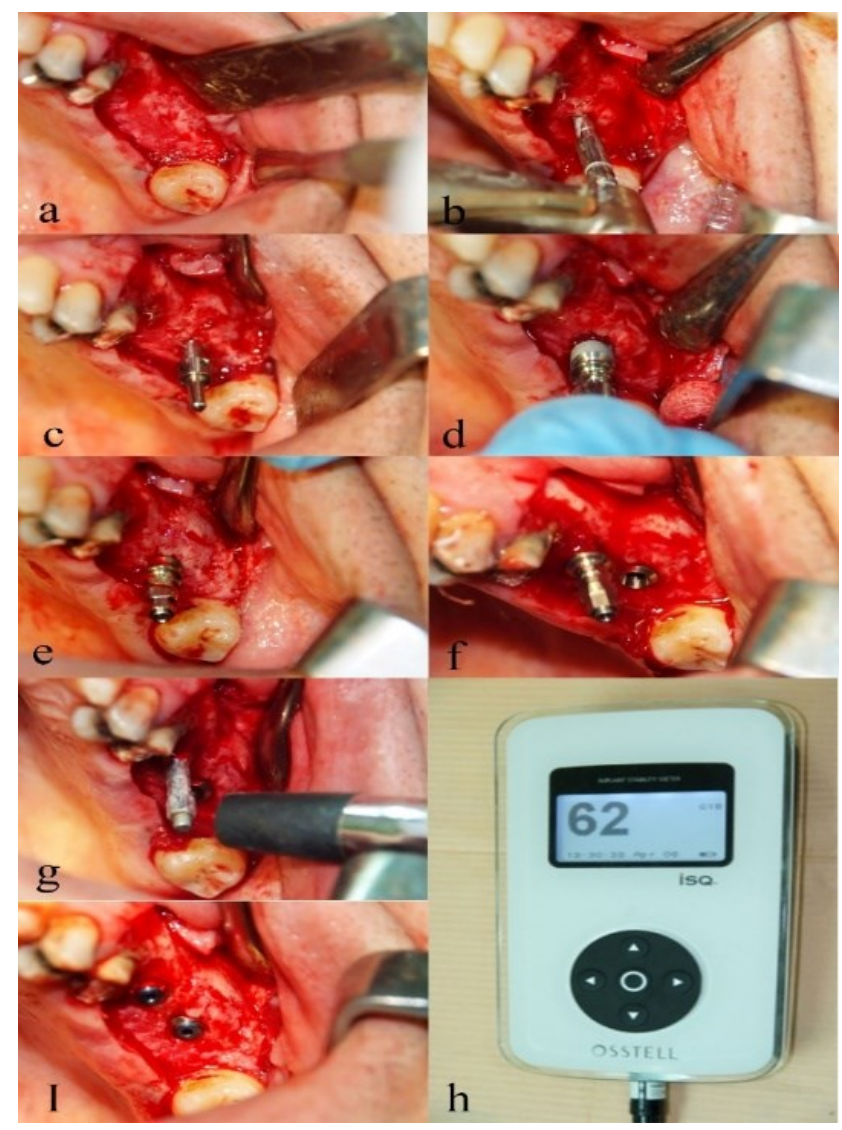

Figure 2: A photograph showing the implant placement surgical procedures and implant stability measurement. a: Mucoperiosteal flap reflection, b: Pilot drill, c: Parallel pins, d: Implant insertion, e: First implant with abutment, f: Second implant with abutment, g: The smart peg is connected to the implant, h: ISQ reading by Osstell.

\section{Bleeding on probing}

Bleeding on probing was evaluated using Mühlemann Papillary Bleeding Index (17) (PBI). Bleeding was provoked by sweeping the sulcus using a periodontal probe under light finger pressure from the base of the papilla to its tip along the distal and mesial aspects of the implant and waiting for 20 seconds. The intensity of bleeding was scored in four grades as follows:

1. A single bleeding point was observed.

2. A fine line of blood or several bleeding points became visible at the gingival margin.

3. The interdental triangle became more or less filled with blood.

4. Profuse bleeding immediately after probing, blood flew into the interdental area to cover portions of implant or gingiva.

\section{Probing depth}

It was measured on all axial surfaces of all implants according to a standard procedure described by Glavind and Löe (18) to measure pocket depth that refers to the distance from the gingival margin to the bottom of the clinical pocket.

\section{Implant Stability Evaluation}

The implant stability measurement was examined at the time of insertion and 6 months postoperatively using the Resonance 
Frequency Analysis via the Osstell ISQ, after each measurement, the ISQ values were recorded and used as the baseline for the next measurement performed. A change in the ISQ value reflected a change in implant stability.

\section{Radiographic Evaluation}

Orthopantomogram (OPG) and cone beam computed tomography (CBCT) were performed immediately postoperative and at intervals of 1, 3 and 6 months to assess:

Position of the implant, assessment of the marginal bone height around the implants by using the Image $\mathrm{J}$ program (Version 1.31 from of the National Institute of Health (USA), measurements of bone density around the implant were done in grayscale, the exposure was performed using $\mathrm{X}$ Ray Tube (98 $\mathrm{kV}$, 3-6 mA), Field of View (FOV) $(15.4 \times 15.4 \times 15.4 \mathrm{~cm})$, Voxel Size $(150 \mu \mathrm{m} / 300 \mu \mathrm{m})$, Effective Dosage (28-154 $\mu \mathrm{Sv})$, Scan Time (14 s/2-5 sec).

Densitometric analysis was performed around dental implants on CBCT image by using "SICAT GALILEOS Implant" software. This analysis gives the bone density around the immersed dental implants by grayscale.

Final prosthesis (porcelain fused to metal crown) was placed after 6 months.

\section{STATISTICAL ANALYSIS OF THE DATA}

Data were fed to the computer and analyzed using IBM SPSS software package version 20.0 (19). Quantitative data were described using range (minimum and maximum), mean, standard deviation and median. Significance of the obtained results was judged at the $5 \%$ level.

\section{The used tests were}

\section{1 - Paired t-test}

For normally quantitative variables, to compare between two periods.

\section{2 - ANOVA with repeated measures}

For normally quantitative variables, to compare between more than two periods or stages, and Post Hoc test (LSD) for pairwise comparisons.

\section{RESULTS}

Twenty implants were placed in ten patients; each patient received two implants ( 2 females and 8 males) having missing maxillary posterior teeth with limited bone height below the maxillary sinus (7-9 $\mathrm{mm}$ ) were included in this study their ages ranged between (40-55) years with mean age of 47 years. They were selected from the Outpatient Clinic of the Oral and Maxillofacial Surgery Department, Faculty of Dentistry, Alexandria University. All patients were followed up both clinically and radiographically for 6 months.

\section{Clinical evaluation}

\section{1- Pain, tenderness, infection or swelling}

There was absence of pain and tenderness on the first postsurgical days during the follow up period. Post-operative edema and discomfort were very minimal and unobserved. Healing was uneventful in all cases with no post-operative swelling or infection.

\section{2- Implant Stability Evaluation}

The implant stability measurement was examined at the time of insertion and $6^{\text {th }}$ months postoperatively using the Resonance Frequency Analysis via the Osstell ISQ system.

The mean implant stability in the immediate postoperative was $(60.30+6.09)$ that value is known as primary stability, the implant stability increased value of
(70.06 \pm 4.61$)$ at 6 th month postoperative respectively (Table 1, Fig 3).

The implant stability was statistically significant at $6^{\text {th }}$ month postoperative compared with immediately measures (Table 1).

\section{3- Bleeding index}

The bleeding index was measured using Mühlemann Papillary Bleeding Index (PBI). The bleeding index was evaluated on the, $6^{\text {th }}$ month, $9^{\text {th }}$ month and $12^{\text {th }}$ month postoperatively.

The bleeding index recorded its value at the $6^{\text {th }}$ month postoperative with mean score $(2.40+0.82)$. It decreased in the subsequent follow up periods to $(2.45+0.51)$ in the 12 month postoperatively.

The bleeding index was statistically not significant at $6^{\text {th }}$ month postoperatively when compared with $9^{\text {th }}$ month postoperative and $12^{\text {th }}$ month postoperatively $(\mathrm{p}=1.00$, $0.789 \& 0.804)$.

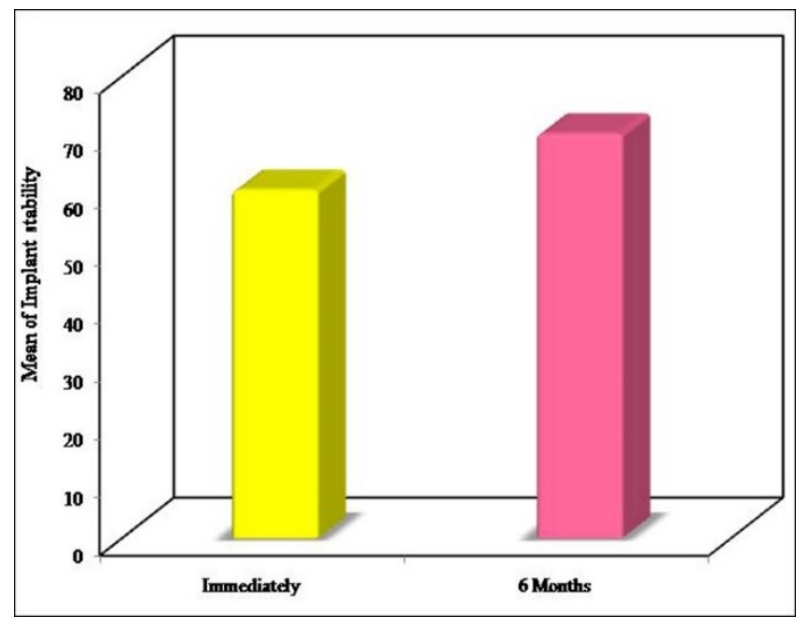

Figure 3: Comparison between the two periods according to implant stability.

Table 1: Comparison between the two periods according to implant stability.

\begin{tabular}{|l|c|c|c|c||}
\hline & $\begin{array}{c}\text { Immediately } \\
(\mathbf{n = 2 0})\end{array}$ & $\begin{array}{c}\mathbf{6} \text { Months } \\
(\mathbf{n = 1 8})\end{array}$ & $\mathbf{t}$ & $\mathbf{P}$ \\
\hline $\begin{array}{l}\text { Implant } \\
\text { stability }\end{array}$ & & & & \\
Min. - & $46.0-70.0$ & $\begin{array}{c}62.0- \\
78.0\end{array}$ & & \\
Max. & & $70.06 \pm$ & & \\
Mean \pm & $60.30 \pm 6.09$ & 4.61 & $0.7690^{*}$ & $<0.001^{*}$ \\
SD. & & 70.0 & & \\
Median & 62.0 & & \\
\hline
\end{tabular}

t: Paired t-test

*: Statistically significant at $\mathrm{p} \leq 0.05$

\section{4- Probing Depth}

The probing depth was measured on all axial surfaces of all implants according to a standard procedure described by Glavind and Löe to measure pocket depth. The probing depth was evaluated on the $6^{\text {th }}$ month, $9^{\text {th }}$ month and $12^{\text {th }}$ month postoperatively.

The mean probing depth of the implant was (217 \pm 0.99$)$ $\mathrm{mm}$ on the $6^{\text {th }}$ month postoperatively. There was gradual decrease of the mean probing depth during the follow up 
period with values of $(2.11 \pm 0.83) \mathrm{mm}$ at the $9^{\text {th }}$ month while at the $12^{\text {th }}$ month postoperative the mean probing depth had increased to reach $(2.61 \pm 0.70) \mathrm{mm}$.

The probing depth was statistically not significant at $6^{\text {th }}$ month postoperatively when compared with that of the $9^{\text {th }}$ month postoperative and with the $12^{\text {th }}$ month postoperatively $(p=0.859)$. The probing depth was statistically significant at $9^{\text {th }}$ month postoperative compared with $12^{\text {th }}$ month $(\mathrm{p}=0.046)$.

\section{Radiographic evaluation (Fig. 4) Assessment of the marginal bone loss}

The bone level changes were measured by using the Image $\mathrm{J}$ program. The mean value of the change in the marginal bone level was calculated and recorded on the $3^{\text {rd }}$, $6^{\text {th }}$ and $9^{\text {th }}$ months in comparison to the base line radiograph which was taken immediately post operatively.

The data collected was tabulated and the statistical analysis of marginal bone level scores was done for all patients. (Table 2, Fig. 5)

The marginal bone loss increased steadily from immediately postoperative $(0.54 \pm 0.10 \mathrm{~mm})$ to $(0.62 \pm 0.12$ $\mathrm{mm})$ at 3 month, and on the $6^{\text {th }}$ month it was $(0.69 \pm 0.15 \mathrm{~mm})$ and on the $9^{\text {th }}$ month it was $(0.79 \pm 0.21 \mathrm{~mm})$. The increase in the marginal bone loss from immediately postoperative with $3^{\text {rd }}, 6^{\text {th }}$ and $9^{\text {th }}$ was statistically significant $(\mathrm{p}=0.001)$.

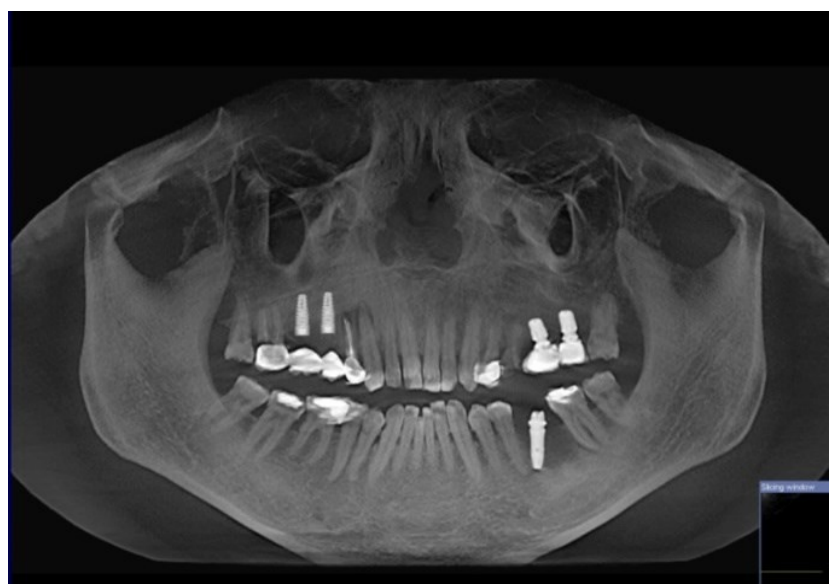

Figure 4: CBCT image of the implant taken $6^{\text {th }}$ month postoperatively.

\section{Bone density}

Densitometric analysis was performed around dental implants on CBCT image at intervals of immediate, $1^{\text {st }}$ month, $3^{\text {rd }}$ month and $6^{\text {th }}$ month postoperatively using the "SICAT GALILEOS Implant" software. This analysis gives the bone density around the immersed dental implants by grayscale.

The mean bone density was $(1522.0 \pm 137.14)$ at the site of implant placement preoperative. There was an increase in mean bone density postoperative during the whole follow up period with values of (1649.50土 102.93), $(1832.95 \pm 92.41),(1934.25 \pm 82.72)$ at $1^{\text {st }}$ month, $3^{\text {rd }}$ month and $6^{\text {th }}$ month postoperative respectively (Table 3 ).

The mean bone density was statistically significant at, $1^{\text {st }}$ month, $3^{\text {rd }}$ month and $6^{\text {th }}$ month postoperatively when compared with the preoperative bone density measurement $(\mathrm{p}<0.00)$ (Table 3, Fig. 6).

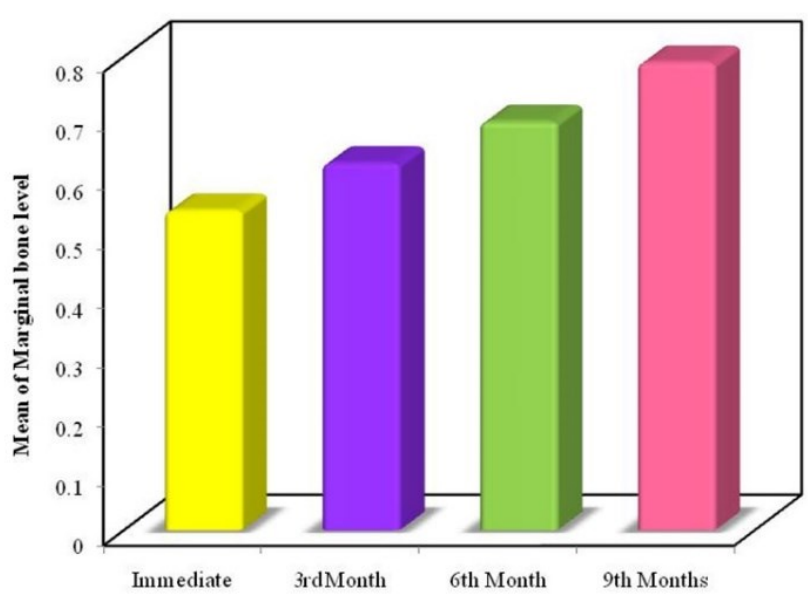

Figure 5: Comparison between the different periods according to marginal bone loss.

Table 2: Comparison between the different periods according to marginal bone loss.

\begin{tabular}{|c|c|c|c|c|c|c|}
\hline & $\begin{array}{c}\text { Immediate } \\
(\mathrm{n}=18)\end{array}$ & $\begin{array}{c}3^{\text {st }} \\
\text { Month } \\
(\mathrm{n}=18)\end{array}$ & $\begin{array}{c}6^{\text {rd }} \\
\text { Month } \\
(n=18)\end{array}$ & $\begin{array}{c}9^{\text {th }} \\
\text { Months } \\
(n=18)\end{array}$ & $F$ & $\mathrm{p}$ \\
\hline \begin{tabular}{|l} 
Marginal \\
bone \\
level \\
Min. - \\
Max. \\
Mean \pm \\
SD. \\
Median
\end{tabular} & $\begin{array}{c}0.39- \\
0.78 \\
0.54 \pm \\
0.10 \\
0.51\end{array}$ & $\begin{array}{c}0.48- \\
0.96 \\
0.62 \pm \\
0.12 \\
0.58\end{array}$ & $\begin{array}{c}0.44- \\
1.04 \\
0.69 \pm \\
0.15 \\
0.70\end{array}$ & $\begin{array}{c}0.43- \\
1.18 \\
0.79 \pm \\
0.21 \\
0.77\end{array}$ & $23.555^{\circ}$ & $<0.001^{*}$ \\
\hline \begin{tabular}{|c|} 
pImm. \\
$\begin{array}{l}\text { Sig. bet. } \\
\text { periods }\end{array}$ \\
\end{tabular} & & \multicolumn{3}{|c|}{$\begin{array}{c}\mathrm{p}_{1}=0.001^{*}, \mathrm{p}_{2}<0.001^{*} \\
\mathrm{p}_{3}=0.001^{*}\end{array}$} & & \\
\hline
\end{tabular}

F: F test (ANOVA) with repeated measures

Sig. bet. Periods was done using Post Hoc Test (LSD) for ANOVA with repeated measures

pImm.: $p$ value for comparison between Immediate with each other periods

$\mathrm{p}_{1}$ : $\mathrm{p}$ value for comparison between $3^{\text {rd }}$ Month with $6^{\text {th }}$ Month p2: $p$ value for comparison between $3^{\text {rd }}$ Month with $9^{\text {th }}$ Month $\mathrm{p}_{3}$ : $\mathrm{p}$ value for comparison between $6^{\text {th }}$ Month with $9^{\text {th }}$ Month *: Statistically significant at $\mathrm{p} \leq 0.05$

Table 3: Comparison between the different periods according to bone density.

\begin{tabular}{|c|c|c|c|c|c|c|}
\hline & $\underset{(n=20)}{\text { Immediate }}$ & $\begin{array}{c}1^{\text {st }} \text { Month } \\
(n=20)\end{array}$ & $\begin{array}{c}3^{\text {rd }}{ }_{(n=20)}^{\text {Month }} \\
\end{array}$ & $\begin{array}{c}6^{\text {th }} \text { Months } \\
(n=20)\end{array}$ & $\mathbf{F}$ & p \\
\hline Bone density & & & & & & \\
\hline Min. - Max. & $1300.0-1790.0$ & $1400.0-1800.0$ & $1650.0-1995.0$ & $1750.0-2000.0$ & & \\
\hline Mcan \pm SD & $1522.0 \pm 137.14$ & $1649.50 \pm 102.93$ & $1832.95 \pm 92.41$ & $1934.25 \pm 82.72$ & $129.517^{\circ}$ & $<0.001^{\circ}$ \\
\hline Mcdian & 1525.0 & 1670.0 & 1865.0 & 1985.0 & & \\
\hline Sig. bet. periods & \multicolumn{4}{|c|}{$\mathrm{p}_{1}<0.001^{*}, \mathrm{p}_{2}<0.001^{*}, \mathrm{p}_{3}<0.001^{*}, \mathrm{p}_{4}<0.001^{*}, \mathrm{p}_{5}<0.001^{*}, \mathrm{p}_{6}<0.001^{*}$} & & \\
\hline
\end{tabular}

F: F test (ANOVA) with repeated measures

Sig. bet. Periods was done using Post Hoc Test (LSD) for ANOVA with repeated measures

$\mathrm{p}_{1}$ : $\mathrm{p}$ value for comparison between immediate with $1^{\text {st }}$ Month $\mathrm{p}_{2}$ : $\mathrm{p}$ value for comparison between immediate with $3^{\text {rd }}$ Month p3: $p$ value for comparison between immediate with $6^{\text {th }}$ Month p4: $p$ value for comparison between $1^{\text {st }}$ Month with $3^{\text {rd }}$ Month p5: $p$ value for comparison between $1^{\text {st }}$ Month with $6^{\text {th }}$ Month p6: $p$ value for comparison between $3^{\text {rd }}$ Month with $6^{\text {th }}$ Month *: Statistically significant at $\mathrm{p} \leq 0.05$ 


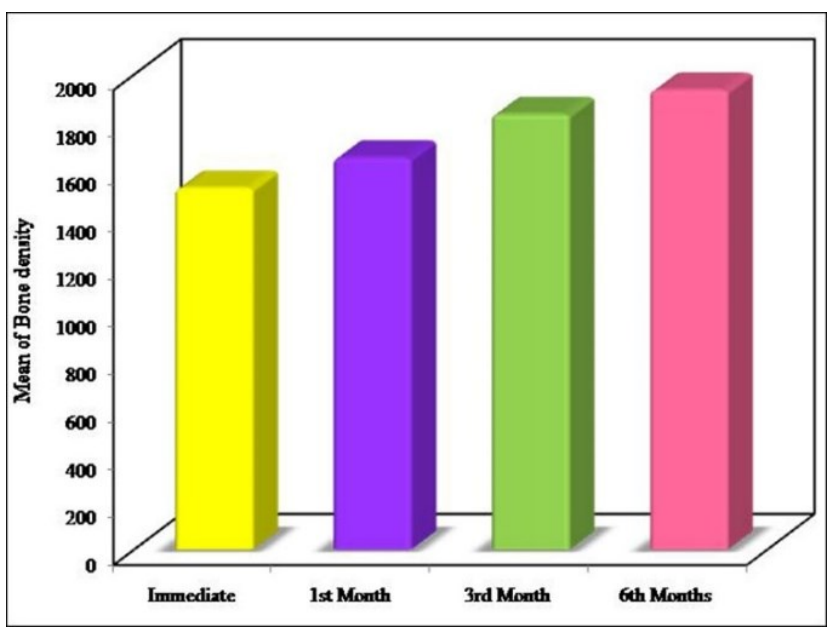

Figure 6: Comparison between the different periods according to bone density.

\section{DISCUSSION}

Inadequate alveolar bone height is a common limitation to properly placed endosseous root-form dental implant in the posterior maxilla (20).

The present study was designed to evaluate clinically and radiographically the osseointegration, bone level, bone density and stability around short implants simultaneously inserted in atrophic posterior maxilla. In this study 10 patients with deficient alveolar bone height were selected for the study. The selected patients were free from any systemic diseases or a condition that may complicate the surgical procedure or the healing process of the implant this was following Bornstein et al., (21) in 2009 where they reviewed whether systemic diseases with/without systemic medication increase the risk of implant failure and therefore diminish success and survival rates of dental implants.

Recent studies demonstrated that uncontrolled diabetes may lead to high incidence of implant failure. This could be attributed to the fact that normal metabolism of phosphorus and calcium is essential for bone mineralization \& remodeling and is affected by hyperglycemia. The latter alters the response of parathyroid hormone. In addition, diabetes mellitus inhibits osteooblastic differentiation, impairs circulation and reduces chemotaxis and phagocytosis of neutrophils thus increasing the susceptibility for infection (22,23).

All patients in the current study were non smokers. Nicotine, which is the major component of tobacco, is cytotoxic and prevents differentiation of osteoblasts like cells to osteoblasts thus reducing alveolar bone quality (24).

In addition, the selected patients were not previously exposed to radiotherapy as irradiation locally impairs bone quality and impairs the prognosis of dental implants in the long-term as it inhibits and reduces bone formation. Furthermore, an experimental study that implants placed in irradiated dog mandibles had less bone to implant contact than those placed in non- irradiated controls. Different other findings have shown that the failure rate of endosseous dental implants in irradiated jaw bone can range up to $30 \%$ (25).

Moreover all selected cases were selected free from parafunctional habits such as bruxism and clenching, which increase the magnitude of the forces. In such patients the duration of the forces are extensive and their direction is more horizontal than axial to the implants (26).
Regarding the surgical procedure, all included patients were subjected to delicate surgery using delayed implant placement protocol for the study.

Preoperative radiographic examination was obtained for each patient to determine the presence or absence of any remaining roots or pathosis and to examine the maxillary sinus for any opacities and height of the ridge.

The study recommends minimal $7 \mathrm{~mm}$ of residual bone height. Rios et al., (27) in 2009, reviewed the influence of the remaining alveolar bone upon implant survival and they concluded that a higher implant survival predictability as available residual bone increases.

In the present study, the bleeding index, and probing depth was evaluated along the follow up period. Those clinical parameters and its results influence the implant survival rate and success rate as it depends on the presence of acceptable soft tissue status (peri-implant tissue health).

The radiographic follow up in the present study showed that mean marginal bone loss increased during the whole follow up period. The crestal bone loss for the present investigation was increased approximately from $0.51 \mathrm{~mm}$ immediately to $0.7 \mathrm{~mm}$ after 6 months and $0.77 \mathrm{~mm}$ at 9 months. The crestal bone remodeling was reported to occur predominately during the unloaded healing phase (28).

This agrees with the study of Kim et al., (29) in 2011 who studied the surrounding tissue condition of the sinus bone grafts with simultaneous implant placement of 61 implants. They found that mean marginal bone loss at $6^{\text {th }}$ month was $0.86 \mathrm{~mm}$.

In the present study the bone density was evaluated from the $\mathrm{CBCT}$ radiographs. The bone density preoperatively was the lowest value during the follow up. This could be explained by the poor quality of the bone in the posterior maxilla. The bone quality in the selected patients ranged between the D3 and D4. This was in agreement with the results of Sogo et al., (30) where they studied the bone quality of the posterior maxilla in 30 patients and they concluded that the bone in the posterior maxilla consisted bone that was classified as D3 (350-850 HU) or D4 (150-350 HU) according to Misch's classification, comprising $50 \%$ and $32 \%$ of the entire regions, respectively.

In the subsequent follow up periods the bone density around the implants increased this was due to the compression of bone produced by implant placement technique. The bone density increased around the implant at 3 months and 6 months postoperative. That was explained by the healing of the bone around implants and osseointegration of dental implants.

These results were in agreement with the results of Yunus (31) in 2011. In his study, 30 patients were evaluated using CT to determine the changes of jaw bone density around the dental implant after placement. The study concluded that bone density around dental implant was increased after placement. The increased rate of bone density could be determined by the quality of jaw bone before implant placement.

In the present study, the implant stability was measured using the Resonance Frequency Analysis (RFA) via the Osstell ISQ system.

Meredith et al., $(15,32)$ concluded that RFA is a method that can serve as a useful research technique and may prove to be valuable in studying the behavior of implants in surrounding tissue. In this study a non-contacting method is used allowing the testing of the implant stability from any surface in $360^{\circ}$ around the implant fixture. 
The mean implant stability in the immediate postoperative period was $60.30 \pm 6.09$ that value is known as primary stability that indicates a high primary stability. The high primary stability is contributed to surgical technique and implant taper.

Insertion of the implant into a standard parallel-sided hole increased the primary stability of the implant. The idea behind this approach is to induce controlled compressive forces in the cortical bone layer as the implant is inserted; these forces would increase the primary stability of the implant, and would transfer the region of highest stress/strain to the cortical layer where it will be better tolerated (33).

In another study Yoon et al., (34) in 2011 studied the influence of bone quality and surgical technique on the ISQ value and they concluded that both bone quality and surgical technique have influence on the implant primary stability, and resonance frequency has a positive relation with the density of implant fixture-surrounding bone.

Tukyilmazet al., (35) compared two different surgical techniques for enhancing primary stability in the posterior maxilla. The results of his study suggest using thinner drills for implant in the maxillary posterior region where bone quality is poor may improve the primary stability and help clinicians to obtain higher implant survival rates.

The surface treatment of the implant placed in the posterior maxilla had a role in the increase of the ISQ value in the present study during the healing period. All the implant placed during the study has SLA treated surface where a combination of blasting and acid treatment. That treatment proved to increase in alkaline phosphtase activity, DNA absorption in 3H chimicin's and collagenase which in turn increased the bone deposition around the dental implants $(36,37)$.

Glauser et al., (36) has reported that implant design and surface treatment have a significant influence on soft bone. In a study for surface treatment effect on the stability Kim et al., (37) reported that surface treatment may have significant effects on biological stability 3 weeks after implant placement.

Moreover, Farré-Pagés et al., (38) studied the relation between the bone quality and primary stability and they concluded that there is no relation between the ISQ value and bone quality.

In the present study, the implant stability had been increased. Although in the current study there is a marginal bone loss but the stability increased throughout the follow up period this was explained by the effect of bone loss was compensated for by an increased interfacial stiffness resulting from bone formation and remodeling. The ongoing healing process may have counteracted and masked the effect of marginal bone loss.

\section{CONCLUSIONS}

The use of short implants in atrophic posterior maxilla provides clinicians with a more conservative option of the treatment and help to minimize treatment duration, cost and trauma.

Short implants might be a preferable choice to place in atrophic posterior maxilla.

\section{CONFLICT OF INTEREST}

The authors declare that they have no conflicts of interest.

\section{ACKNOWLEDGMENTS}

I would like to extend my gratitude to all staff members and colleagues in the Oral and Maxillofacial Surgery Department, Faculty of Dentistry, Alexandria University, for their great help and support.

\section{REFERENCES}

1- Das Neves FD, Fones D, Bernardes SR, do prado CJ, Neto AJ. Short implants-an analysis of longitudinal studies. Int J Oral Maxillofac Implants 2006; 21: 86-93.

2- Renourd F, Nisand D. Impact of implant length and diameter on survival rates. Clin Oral Implants Res 2006; 17: 35-51.

3- Esposito M, Grusovin MG, Felice P, Karatzopoulos G, Worthington $\mathrm{HV}$, Coulthard $\mathrm{P}$. Interventions for replacing missing teeth: horizontal and vertical bone augmentation techniques for dental implants treatment. Cochrane Database Syst Revi 2009; 7: CD003607.

4- Esposito M, Grusovin MG, Kwan S, Worthington HW, Coulthard P. Interventions for replacing missing teeth: bone augmentation techniques for dental implant treatment. Chichester U: John Wiley \& Sons, Ltd., 2008.

5- Fontana F, Santoro F, Maiorana C, Lezzi G, Piattelli A, Simion M. Clinical and histologic evaluation of allogenic bone matrix versus autogenous bone chips associated with titanium-rein-forced e-PTFE membrane for vertical ridge augmentation: a prospective pilot study. Int J Oral Maxillofac Implants 2008; 23: 1003-12.

6- Felice P, Marchetti C, Piattelli A, Pellegrino G, Checchi $\mathrm{V}$, Worthington $\mathrm{H}$, et al. Vertical ridge augmentation of the atrophic posterior mandible with interpostitional block grafts: bone from the iliac crest versus bovine anorganic bone. Results up to delivery of the final prostheses from a split-mouth, randomized controlled clinical trial. Eur J Oral Implantol 2008; 1: 183-7.

7- Hallman M, Senneby L, lundgren S. A clinical and histological evaluation of implants integration in the posterior maxilla after sinus floor augmentation with autogenous bone, bovine hydroxyapatite, or a 20:80 mixture. Int $\mathbf{J}$ of Oral Maxillofac Implants 2002; 17: 635-43.

8- Felice P, Cannizzaro G, Checchi V, Pellegrino G, Censi P, Esposito M. Vertical bone augmentation versus $7 \mathrm{~mm}$ long dental implants in posterior atrophic mandibles. A randomized controlled clinical trial. Eur J Oral Implantol 2009; 2: 7-20.

9- Cannizzaro G, Felice P, Leone M, Viola P, Esposito M. Early loading of hydroxyapatite coated implants in the atrophic posterior maxilla: lateral sinus lift with autogenous bone and Bio-Oss versus cretal mini-sinus lift and $8 \mathrm{~mm}$ implants. A randomized controlled clinical trial. Eur J Oral Implantol 2009; 25-38.

10-Adell R, Lekholm U, Rockler B, Branmark OI. A 15year study of osseointegarted implants in the treatment of the edentulous jaw. Int J Oral Surg 1981; 10: 387-416.

11-Sennerby L, Roos J. Surgical determinants of clinical success of osseointegrated oral implants: a review of the literature. Int J Prosthodont 1998; 11: 408-20.

12-O'Sullivan D, Sennerby L, Meredith N. Measurements comparing the initial stability of five designs of dental implants: a human cadaver study. Clin Implant Dent Relat Res 2000; 2: 85-92. 
13-Martinez H, Davarpanah M, Missika P, Celletti R, Lazzara R. Optimal implant stabilization in low density bone. Clin Oral Implant Res 2001; 12: 423-32.

14-Albrektsson T, Branemark PI, Hansson HA, Lindestrom J. Osseointegrated titanium implants. Requirements for ensuring a long-lasting, direct bone-to implant anchorage in man. Acta Orthop Scand 1981; 52: 155-70.

15-Meredith N, Alleyne D, Cawley P. Quantitative determination of the stability of the implant-tissue interface using resonance frequency analysis. Clin Oral Implants Res 1996; 7: 261-7.

16-Boonstra AM, Schiphorst Preuper HR, Reneman MF, Posthumus JB, Stewart RE. Reliability and validity of the visual analogue scale for disability in patients with chronic musculoskeletal pain. Int J Rehabil Res 2008; 31: 165-9.

17-Muhlemnn HR. Psychological and chemical mediators of gingival health. J preventive Dent 1977; 4: 6-15.

18-Glavind L, Loe H. Errors in the clinical assessment of periodontal destruction. J Periodont Res 1976; 2: 180-4.

19-Kirkpatrick LA, Feeney BC. A simple guide to IBM SPSS statistics for version 20.0. Student ed. Belmont, Calif.: Wadsworth, Cengage Learning, 2013.

20-Rosen MD, Sarnat BG. Change of volume of the maxillary sinus of the dog after extraction of adjacent teeth. Oral Sur Oral Med Oral Pathol 1955; 8: 420-9.

21-Bornstein MM, Cionca N, Mombelli A. Systemic conditions and treatments as risks for implant therapy. Int J Oral Maxillofac Implants 2009; 24: 12-27.

22-Leonhardt A, Dahlen G, Renvert S. Five- year clinical, microbiological and radiological outcome following treatment of peri- implantitis in man. J Periodontol 2003; 74: 1415-22.

23-Inbarajan A, Veeravalli PT, Vaidyanathan AK, Grover M. Short-term evaluation of dental implants in a diabetic population: an in vivo study. J Adv Prosthodont 2012; 4: $134-8$.

24-Nociti F, Cesar N, Carvalho M, Sallum E. Bone denisty around titanium implants may be influenced by intermittent cigarette smoke inhalation: A histometric study in rats. Int J Oral maxillofac Implants 2002; 17: 347-52.

25-Visch L, Van Waas M, Schmitz P, Levendag P. A clinical evaluation of implants in irradiated oral cancer patients. J Dent Res 2002; 81: 856-9.

26-Manfredini D, Poggio CE, Lobbezoo F. Is Bruxism a risk factor for dental implants? A Systemic Review of the Litrature. Clin Implant Dent Relat Res 2012; 16: 460-9.

27-Rios HF, Avila G, Galindo P, Bratu E, Wang HL. The influence of remaining alveolar bone upon lateral window sinus augmentation implant survival. Implant Dent 2009; 18:402-12.
28-Nedir R, Bischof M, Vazquez L, Szmukler-Moncler S, Bernard JP. Osteotome sinus floor elevation without grafting material: a 1-year prospective pilot study with ITI implants. Clin Oral Implants Res 2006; 17: 679-86.

29-Kim SJ, Kim MR, Rim JS, Chung SM, Shin SW. Comparison of implant stability after different implant surface treatmen ts in dog bone. J Appl Oral Sci 2010; 18: 415-20.

30-Sogo M, Ikebe K, Yang TC, Wada M, Maeda Y. Assessment of bone density in the posterior maxilla based on Hounsfield units to enhance the initial stability of implants. Clin Implant Dent Relat Res 2012; 14: e183-7.

31-Yunus B. Assessment of the increased calcification of the jaw bone with CT-Scan after dental implantplacement. Imaging Sci Dent 2011; 41: 59-62.

32-Meredith N, Book K, Friberg B, Jemt T, Sennerby L. Resonance frequency measurements of implant stability in vivo. A cross-sectional and longitudinal study of resonance frequency measurements on implants in the edentulous and partially dentate maxilla. Clin Oral Implants Res 1997; 8:226-33.

33-Gotfredsen K, Nimb L, Hjorting-Hansen E, Jensen JS, Holmen A. Histomorphometric and removal torque analysis for TiO2-blasted titanium implants. An experimental study on dogs. Clin Oral Implants Res 1992; 3: 77-84.

34-Yoon HG, Heo SJ, Koak JY, Kim SK, Lee SY. Effect of bone quality and implant surgical technique on implant stability quotient (ISQ) value. J Adv Prosthodont 2011; 3:10-5.

35-Turkyilmaz I, Aksoy U, McGlumphy EA. Two alternative surgical techniques for enhancing primary implant stability in the posteriormaxilla: a clinical study including bone density, insertion torque, and resonance frequency analysis data. Clin Implant Dent Relat Res 2008; 10: 231-7.

36-Glauser R, Zembic A, Ruhstaller P, Windisch S. Fiveyear results of implants with an oxidized surface placed predominantly in soft quality bone and subjected to immediate occlusal loading. J Prosthet Dent 2007; 97:S59-68.

37-Kim SJ, Kim MR, Rim JS, Chung SM, Shin SW. Comparison of implant stability after different implant surface treatments in dog bone. J Appl Oral Sci 2010; 18: 415-20.

38-Farré-Pagés N, Augé-Castro ML, Alaejos-Algarra F, Mareque-Bueno J, Ferrés-Padró E, Hernández-Alfaro F. Relation between bone density and primary implant stability. Med Oral Patol Oral Cir Bucal 2010; 16: e62-7. 